\title{
The Effect of Wind Velocity on the Suppression of Composite Wing Airfoil NACA 0012
}

\author{
Hassan Ali Kadhem* Ahmed Abdul Hussein** \\ ***Department of Mechanical Engineering/College of Engineering/University of Baghdad/Iraq \\ *Email: Hali2013201359@ gmail.com \\ **Email: Dr.Ahmed.ali@coeg.uobaghdad.edu.iq
}

(Received 29 April 2019; accepted 19 June 2019)

https://doi.org/10.22153/kej.2019.06.007

\begin{abstract}
The first studies on shocks and vibrations were carried out at the beginning of the 1930s to improve the behavior of buildings during earthquakes. Vibration tests on aircraft were developed from 1940 to verify the resistance of parts and equipments prior to their first use. Flutter is a well-known example of dynamic aero elasticity, where when oscillation of structure interacted with unsteady aerodynamic forces the flutter will occur. Vibration on any structure without damping means that self-harmonic oscillation will occur, and in most cases the oscillation may start to increase until structural failure. This behavior is very similar to resonance phenomena if only the oscillation is being studied as a vibration case. In vibration suppression, the active vibration control is one of the more effective technique which is used for attenuating bad effects of disturbances on structure. In this work, two different composite wings have been used; one of them is made of Glass-fiber random matt and the other is made of woven ( $\{0 / 90\}$ Glass-fiber). The proportionalintegral-derivative (PID) control is employed here for studying the suppression of active vibration wing affected by wind velocity flow through wind tunnel in the laboratory of mechanical engineering department at the university of Baghdad. Piezoelectric (PZT) transducers are used as sensors and actuators in vibration control systems. The attack angle was 10 degrees and three different velocities $(15,20,35 \mathrm{~m} / \mathrm{s})$ have been taken to show their effect on the wings vibrations suppression. Is noticed that the suppression of the wing amplitude is reduced when the wind velocity increases for both woven and random composite wing matt. This is happened due to the vortex which has became more violent with the increase in wind velocity. It is concluded that the composite woven wing has high resistance more than the composite random wing. Also, the maximum control amplitude of woven matt is $1.9 \mathrm{~cm}$ and the damping is about $33 \%$ at $25 \mathrm{~m} / \mathrm{s}$ wind velocity while the amplitude is $2.22 \mathrm{~cm}$ and the damping is about $53 \%$ at $10 \mathrm{~m} / \mathrm{s}$ wind velocity for random wing.
\end{abstract}

Keywords: Wind velocity, Piezoelectric, NACA 0012, proportional-integral-derivative Control.

\section{Introduction}

All the mechanical systems suffer external effects like structure moves through the air. This motion will cause aerodynamic loads which leads to deformations of the structure. The deformation in turn has an impact on the airflow, thus changing the aerodynamic loading. Apparently, there is a closed loop of aerodynamic and structural interactions and depending on the properties of the structure and the airflow, different methods of controlling have been used with many applications to give the reader enough knowledge about it. Different works in the literature were studied the active vibration control techniques [12]. Song Z, Li F. in [1] used derivative of velocity and proportional feedback on two different types of controllers in vibration were used with PZT as sensors and actuator. The ability of suppression of composite plate used for aero elastic analysis is studied. No experimental tests had been presented and the modal analysis of tested model was formulated by MATLAB codes. Results 
show that proportional regulator has high effectiveness in vibration suppression with $31 \%$ and $25 \%$ for free and forced responses respectively.

In [2], composite plate with PZT is used to perform controlling loop. The study is aimed for evaluating the performance of an active regulator for suppression of undesired vibrations. This suppression is carried out via controlling loop and PZT as sensors and actuators totally formulated in finite element (FE) environment. Numerical simulation had been done in ANSYS environment for composite smart plate equipped with PZT. Besides FE model, real model is fabricated and tested experimental for vibration suppression. About 59\% of overall model vibration is suppressed with good agreement between both experimental and numerical responses. PZT in [3] is used to sense the strain of flexible aluminum cantilever beam and fed it back to regulator loop for actively attenuation of its free oscillation. Finite element simulation is performed besides experiments to check the acceptance of measurements. Using national instruments (NI), cRIO 9022 in Lab View is used in controlling loop. Results exhibit high level of agreement between both tests. High performance of regulator feedback to attenuate about $49 \%$ of free oscillation is noticed. The control law has demonstrated $53.91 \%$ and $62.5 \%$ reduction in vibration for the first and second mods respectively.

M. Kerboua, et al in [4] proposed a method called "passive piezoelectric vibration shunt control". In the beginning, the numerical solver is utilized in order to estimate best design and position of PZT. Maximum attenuation that was satisfied in oscillation was leveled by percent of forty two from bending oscillation. The results shown that the efficiency of the control is sensitive to the PZT patch location and the accuracy of the shunt circuit is being tuned. Active flutter suppression is tested for a base profile model of delta wing [5]. The aimed is to provide a numerical approximate to improve the active flutter damping methodology for a fin. The fin was a cantilever aluminum plate like structure with surface enslaved PZT pieces. Surface enslaved PZT pieces which behave as actuators. As a result, the closed loop of the system appeared a transition from a stable condition to unstable condition about $88.6 \mathrm{~m} / \mathrm{s}$ for Single Input Single Output model with $5.4 \%$ improvement and $93.7 \mathrm{~m} / \mathrm{s}$ to Multi Input Multi Output model with $11.4 \%$ improvement.
The work in [6] is focused on introducing general implementation on attenuation of oscillated body. Tested body is a beam fixed from one end and free from another equipped with PZT. First group of PZT were used to measure feedback signal, and another group were for applying controlling force. Such tested model is used in some aerospace applications in which system stability is an important issue. Linear quadratic controller is used as a controlling technique, where excitation of three millimeter is applied at free end of tested model. Linear quadratic regulator is utilized to run regulating process with high performance. Results show high degree of effectiveness in using linear quadratic regulator for attenuation of system oscillation where about $70 \%$ of free body oscillation is eliminated with control on mode.

The study of wind velocity change and show their effect on forced suppression composite wing is a new contribution and also to be ensure of control system response. The results showed the ability of control system to damping the vibration.

The structure of this paper starts with explains about wings which is used in this paper in section 2. Then show the measurement device used in the experimental work in section 3. Section 4 explains lab view program. Section 5 explains experimental description. Section 6 explains the results discussion, finally conclusion in section 7 .

\section{Wings Model}

The aircraft wing has transformed from the wooden and fabric twin-wing set up of the Wright brothers' Flyer, to the composite materials used in the latest models coming off the production line today from the likes of Boeing and Airbus. Aircraft designer have designed several wing types that have different aero dynamic properties. Two composite wings were fabricated by skinning foam model. The foam model was made by cutting the foam via hot wire by passing the hot wire around the aluminum airfoil's shape getting from $\mathrm{CNC}$ machine as shown in Fig 1. The two foam models were skinning by Glass-fiber matt one with random and the other with woven $(\{0 / 90\}$ Glass-fiber). Two layer of Glass-fiber matt for each random and woven Every layer were coated by mixture of Resin, Thickener powder and Hardener. The two wig dimensions were as shown in Fig 2. 


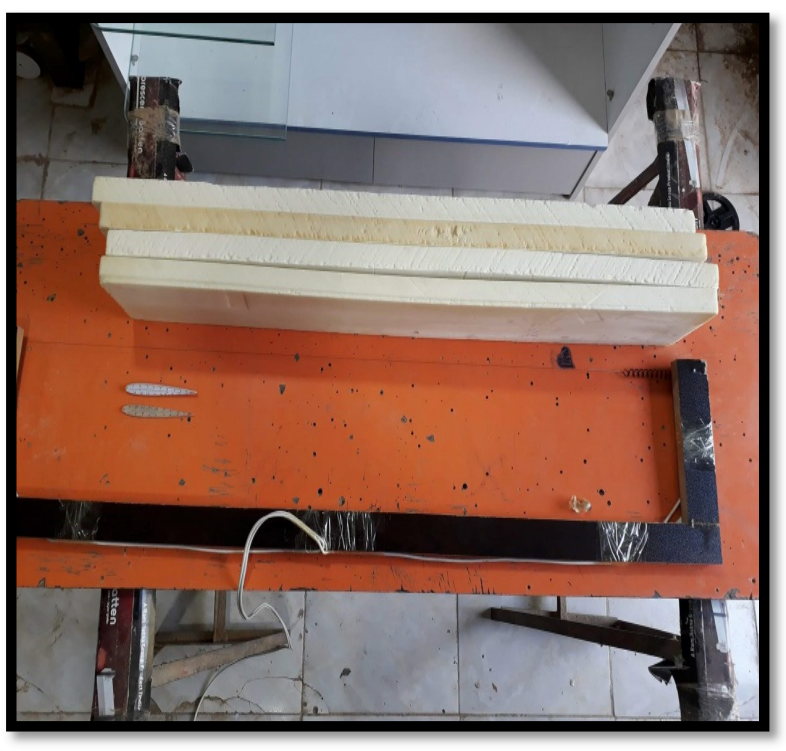

Fig. 1. The hot wire device.

\section{Measurements Device}

\subsection{Piezoelectric Transducer}

In this study, an electrical transducer PPA1001 is used as sensor and actuator as well. MID' piezo (standard products, USA) utilize its piezo protection advantage (PPA) to protect the piezo

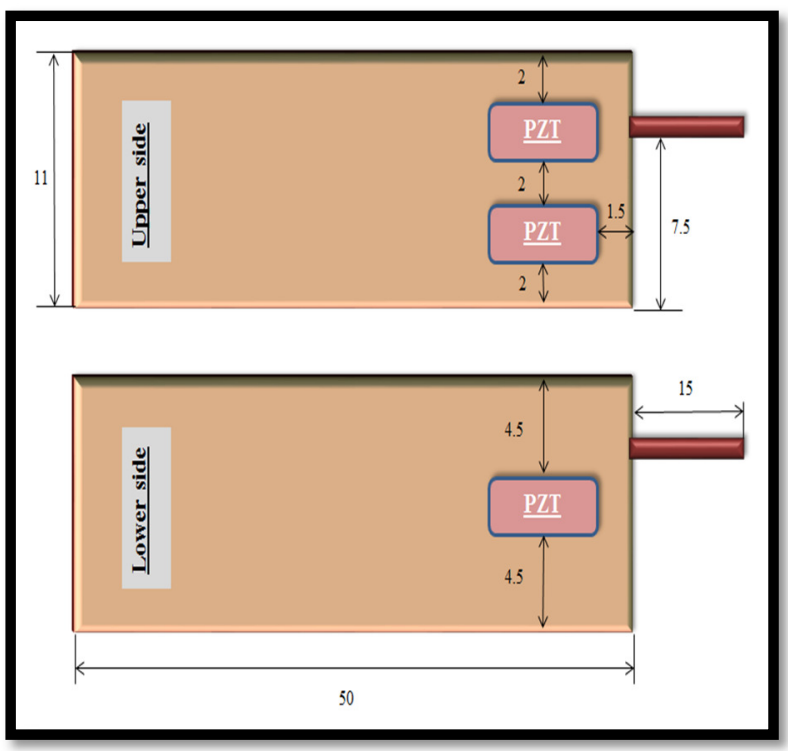

Fig. 2. The dimension of the device.

ceramic wafers. The PPA- 1001 is a single layer product recommended for actuating, energy harvesting and sensing applications. It also exhibits good performance as a resonant actuator [7]. PPA-1001 is presented in Fig 3.

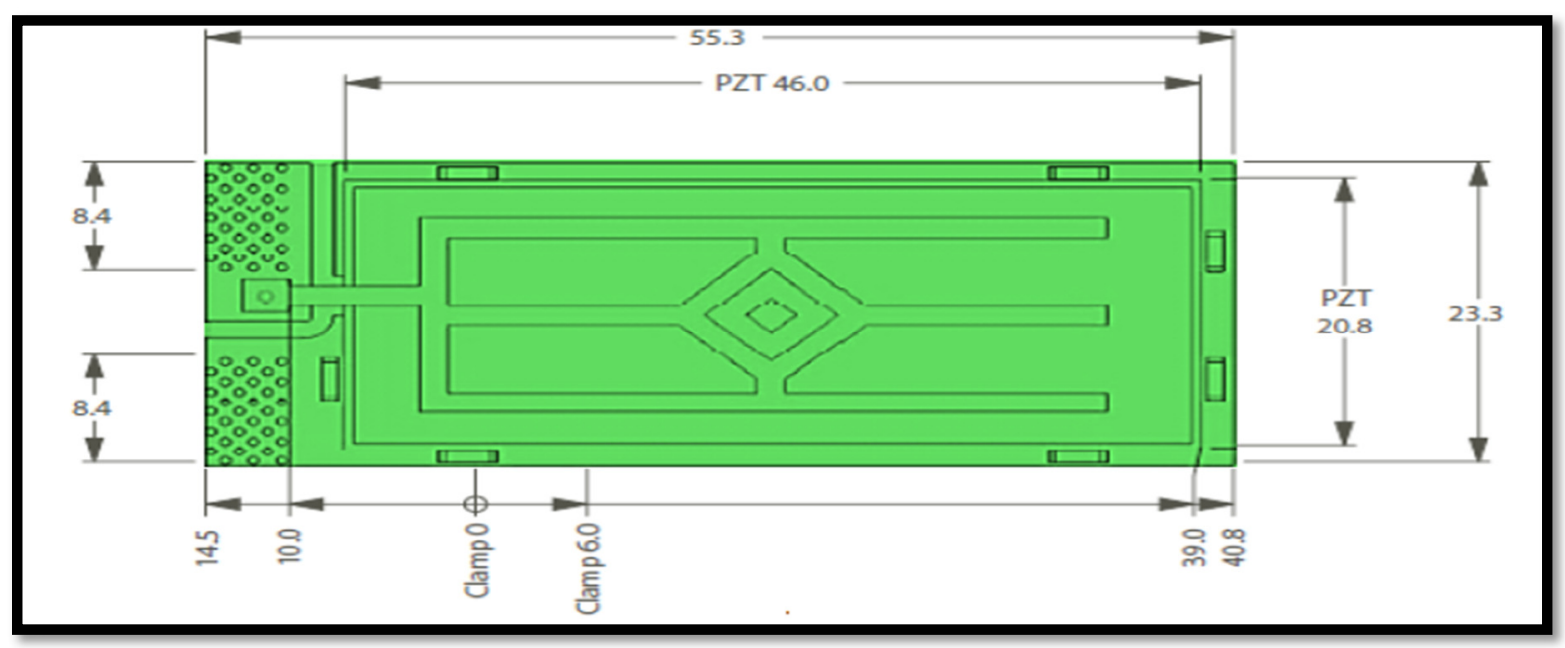

Fig. 3. PPA-1001 transducer with its dimension in ( $\mathrm{mm})$.

\subsection{Compact DAQ-9178 Chassis (National Instruments)}

It is an 8-slot (National Instruments. USA) compact DAQ, USB chassis as shown in Fig 4 is designed for mixed-measurement, small, portable test systems. It combines sensor measurements with voltage, current, and digital signals to create custom mixed system with simple USB cable back to personal computer [8].

\subsection{Analog Input (NI 9215)}

Module compatible with NI compact-DAQ chassis contains four simultaneous sampled analog input channels. Channel to earth ground 
double isolation barrier with NIST-traceable calibration are included for system safety and noise filtering respectively. Also, high range of voltage is available common mode. Range of Analog input is $\pm 10 \mathrm{~V}, 100 \mathrm{Ks} / \mathrm{s}$ per channel with 16-bit sampling rate resolution [9]. NI 2915 is designed to work within temperature range of $(-40$ $\sim 70)$. NI 9215 is one of national instrument products and is presented in Fig. 5.

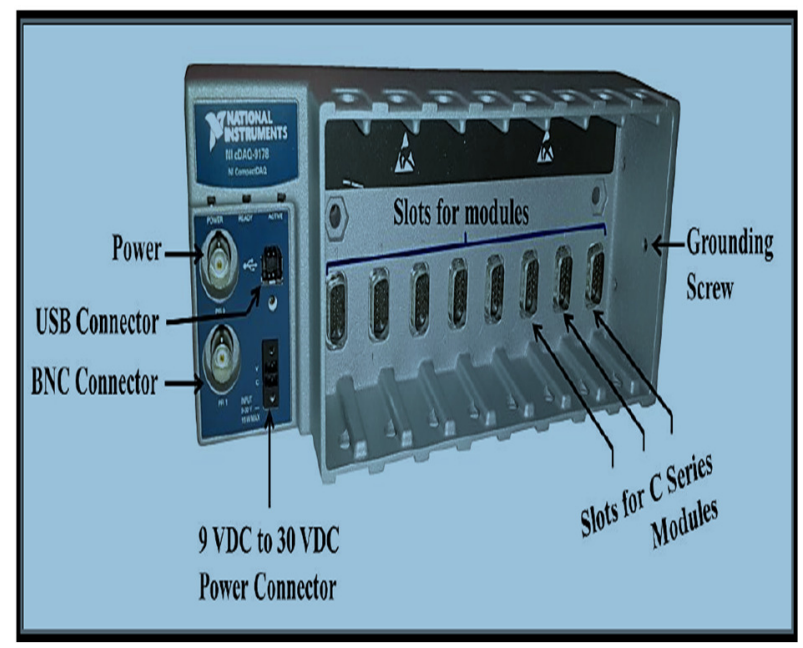

Fig. 4. NI compact DAQ -9178.

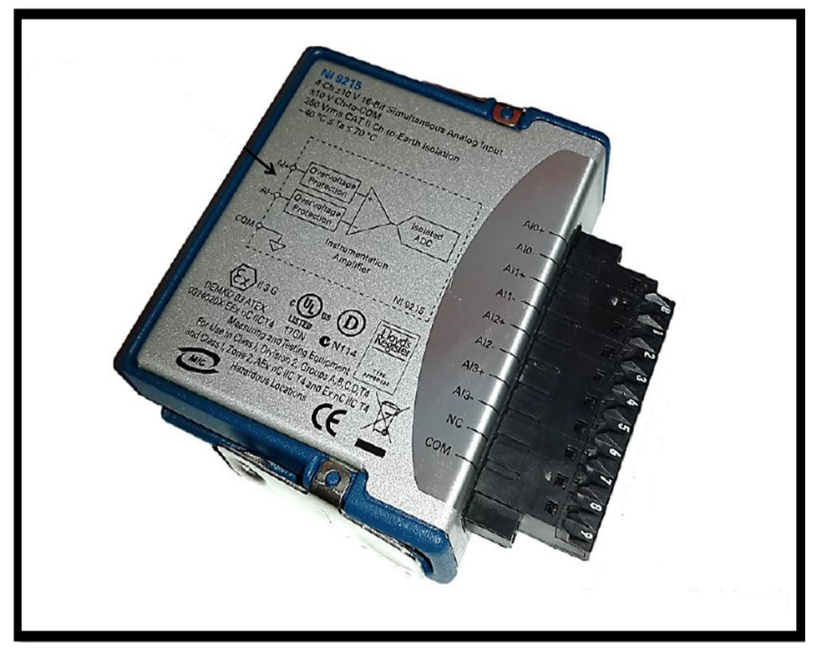

Fig. 5. NI 9215- Analog input voltage.

\subsection{Signal Amplifier}

Two signal amplifiers are used for actuators. The devices used in this work are high voltage inverted operational amplifier (model 2205.USA) presented in Fig 6. Each amplifier has the ability to amplify voltage up to $\pm 500 \mathrm{~V}$, output current range and bandwidth are $\pm 80 \mathrm{~mA}$ and $75 \mathrm{kHz}$ with $3 \mathrm{~dB}$ respectively with maximum output power of 40 W. Safety of measurements against overloading the actuator was provided by such amplifier to protect both amplifier circuit \& PZT from any damage caused by high input voltage or power [10].

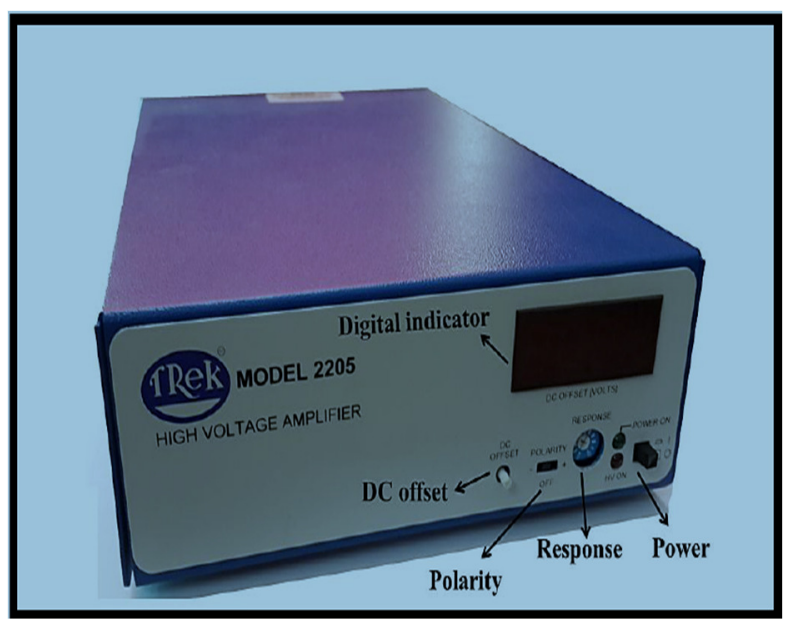

Fig. 6. Signal amplifier.

\section{LABVIEW Program}

The active control program developed in Labview and it used to apply active vibration [14]. Labview contains an inclusive set of tools for storing data, acquiring, and analyzing [15]. In Lab view program the signal input is received, processing and then sent as output signal at step time of $0.001 \mathrm{~s}$ to avoid shifting between the signals input and output [11]. The parameters (Gain K, Proportional Gain Kp, and Integral Gain Ki) of the PID control must be adjusted to have suitable response against the signal of the piezo sensor. By try and error method, the magnitude of three parameter has been tested and the best value of the parameter is used in LabView and that best values of the parameters were $(\mathrm{Kd}=6, \mathrm{Kp}=1$, $\mathrm{Ki}=0.01$ ). A block diagram of the controller that used in this work is presented in Fig. 7. 


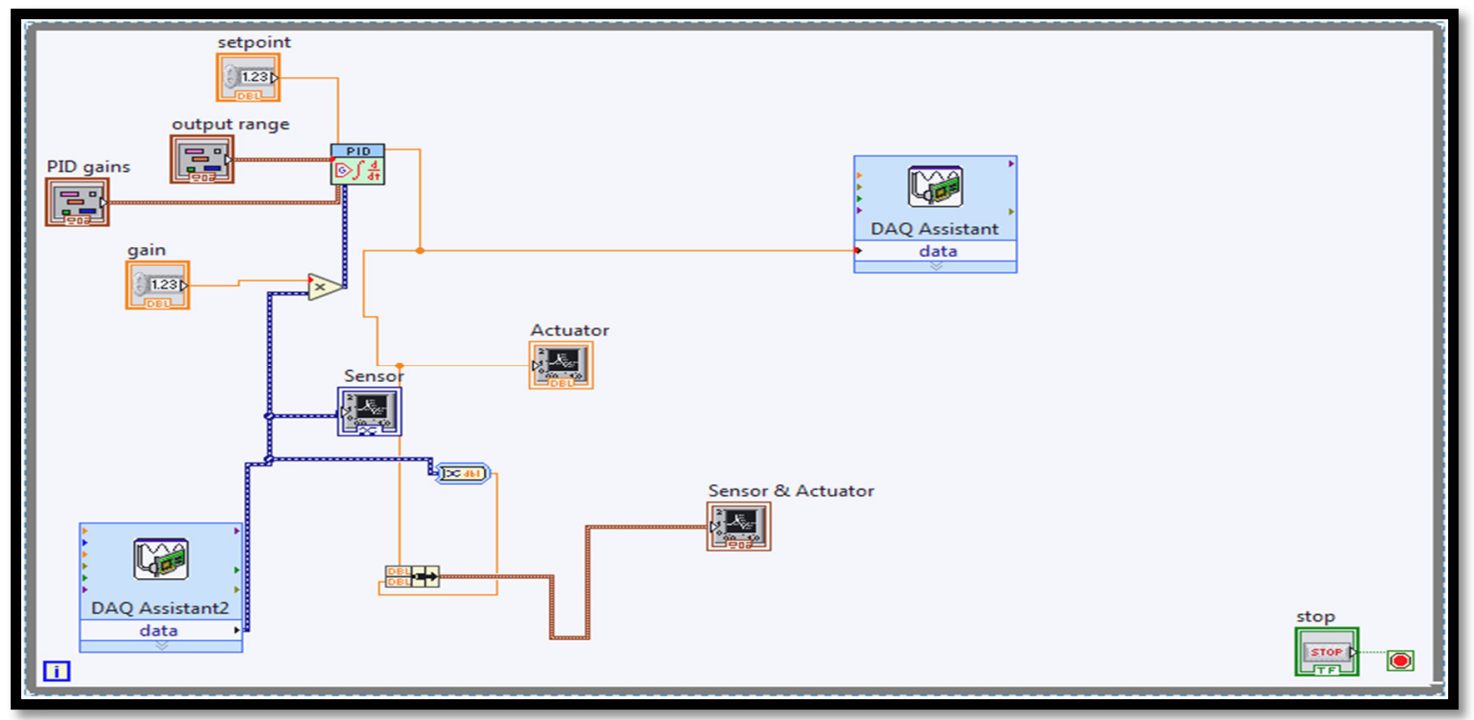

Fig. 7. Block diagram of the controller used in this work.

\section{Experimental Description}

The experimental system used in this work shown clearly in Fig 8 . The displacement responses of tested wing is sensed as voltage by piezoelectric, then forwarded this voltage to an analog input (NI 9215) which is used for noise filtering and acquiring data. However, by importing the relation between sensed voltage and displacement, voltage will be converted to its real value in labview through DAQ which is used to convert sensed signal from analog to digital signal. The output actuators' signals are simultaneously sent through DAQ to analog output card. Then the controlling actuators' signals are sent to high voltage amplifier to drive the piezoelectric actuators which will act by opposite action to wing vibration to damping the vibration of the wing.

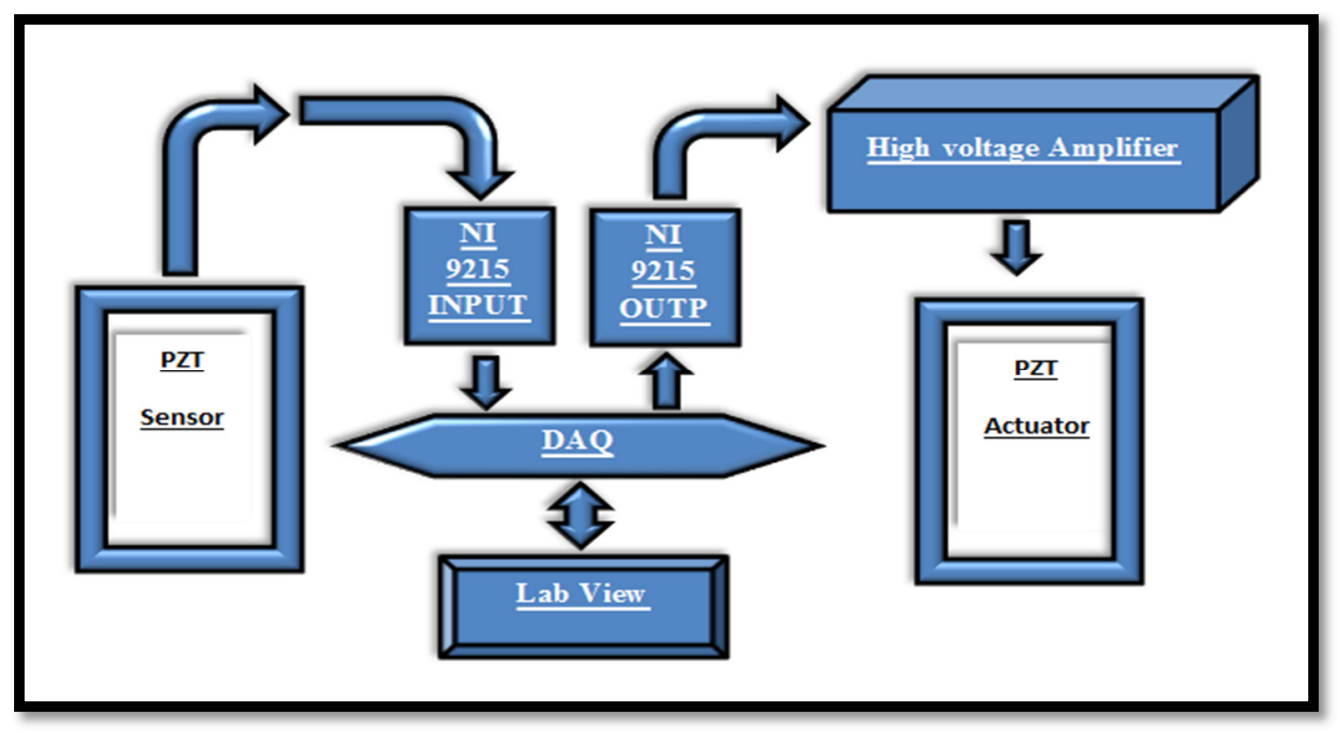

Fig. 8. The diagram of experimental active vibration control.

\section{Results and Discussion}

It has been noticed that the suppression of the wing amplitude is reduced when the wind velocity increases for both woven and random composite wing matt as it compares with free amplitude response. This happens due to the vortex which becomes more violent at the increase of wind velocity as shown in Fig. 9 and Fig. 10. 


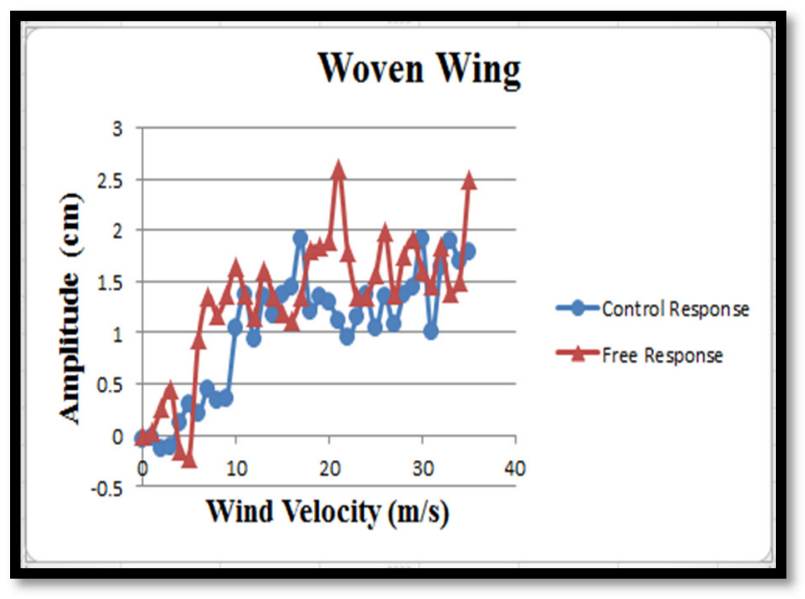

Fig. 9. Relation between wind velocity and Controlling Amplitude.

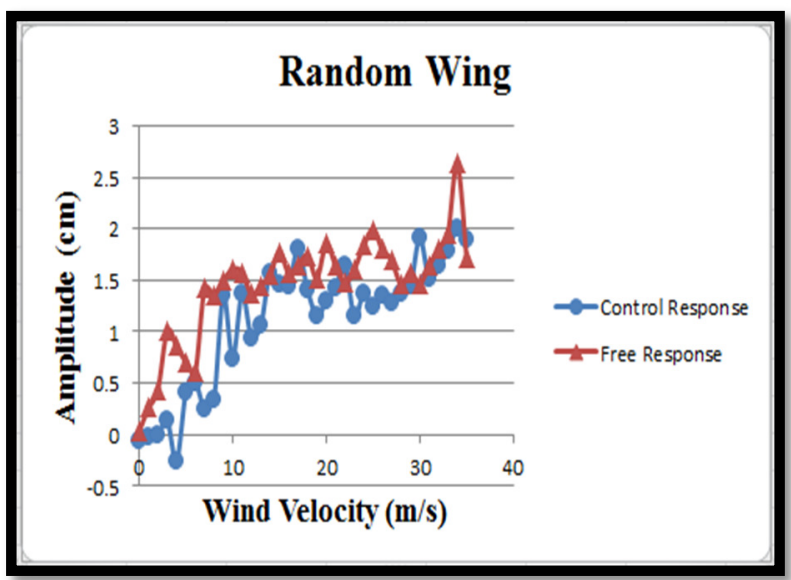

Fig. 10. Relation between wind velocity and Controlling Amplitude.

\section{Conclusion}

The amplitude of control response increases when the wind velocity increases for both woven and random composite wing matt. The composite woven wing has high resistance more than composite random wing. The maximum control amplitude of woven matt is $1.9 \mathrm{~cm}$ and the damping was about $33 \%$ at $25 \mathrm{~m} / \mathrm{s}$ wind velocity while it was $2.22 \mathrm{~cm}$ and the damping was about $53 \%$ at $10 \mathrm{~m} / \mathrm{s}$ wind velocity for random wing.

\section{Reference}

[1] Song, Z Li F. "Active Aeroelastic Flutter Analysis and Vibration Control of Supersonic Composite Laminated Plate", Composite Structures, vol. 94, pp. 702-13, 2012.
[2] Xingjian Dong, Zhike Peng, Lin Ye, Hongxing Hua and Guang Meng. "Performance Evaluation of Vibration Controller for Piezoelectric Smart Structures in Finite Element Environment", Journal of Vibration and Control, vol. 20, 2014.

[3] Riessom, W Rao, P Scholar, PG Krishina, P Gangadharan, K V. "Strain Feedback Active Vibration Control of Smart Cantilever Beam", vol. 5, pp. 113-122, 2014.

[4] Kerboua, M Megnounif, A Benguediab, M Benrahou, KH Kaoulala, MF. "Vibration Control beam using Piezoelectric-based Smart Materials",

Composite Structures, vol. 123, pp. 430-442, 2015.

[5] Fatih, K."Active Flutter Suppression of a Smart Fin", School of Natural and Applied Sciences, Middle East Technical University, Turkey, 2008.

[6] Djojodihardjo, H Jafari, M Wiriadidjaja, S Ahmad, KA. "Active Vibration Suppression of an Elastic Piezoelectric Sensor and Actuator Fitted 152 Cantilevered Beam Configurations as a Generic Smart Composite Structure", Composite Structures, vol. 132, pp. 848-863, 2015.

[7] PPA-1001, Data Sheet, MIDE Co. Ltd., PPAseries 2016.

[8] National Instrument, "Data sheet of Compact DAQ-9178 chassis", USA, 2014.

[9] National Instrument, "Data sheet of DAQ-NI 9215", USA, 2014.

[10] Trek Inc., "Operator's Manual, Model 2205", Piezo Driver/Power Amplifier", USA, 2013.

[11] National Instrument, "Lab VIEW-Control Design User Manual", 2010.

[12] Sebastian Heinze. "Aeroelastic Concept for Flexible Aircraft Structre", Aeronautical and Vehicle Engineering Royal Institute of Technology Stockholm, Sweden, 2007.

[13] Sinusoidal Vibration: Second Edition VolumeChristian Lalanne Copyright 0 2009, ISTELtd

[14] Ghada Adel Aziz. "Simulation Model of Wind Turbine Power Control System with Fuzzy Regulation by Mamdani and Larsen Algorithms", Al-Khwarizmi Engineering Journal,Vol. 13, no. 1, PP. 51- 612017.

[15] Omar Farouq Lutfy and Maryam Hassan Dawood. "Model Reference Adaptive Control based on a Self-Recurrent Wavelet Neural Network Utilizing Micro Artificial Immune Systems" Al-Khwarizmi Engineering Journal, Vol. 13, no. 1, PP. 1071222017. 


\title{
تأثير سرعة الرياح على تخميد أهتزاز جناح مركب ذو بروفويل نوع NACA 0012
}

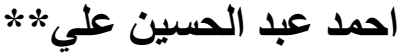 \\ حسن علي كاظمثة

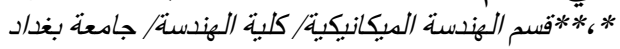

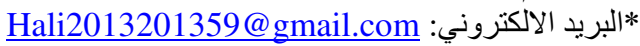

Dr.Ahmed.ali@ coeg.uobaghdad.edu.iq البريد الالكتروني:**

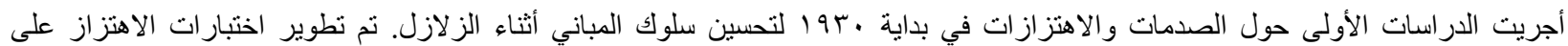

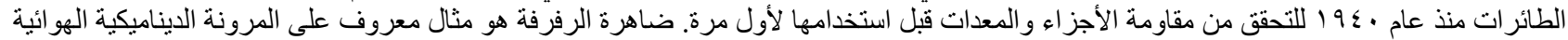

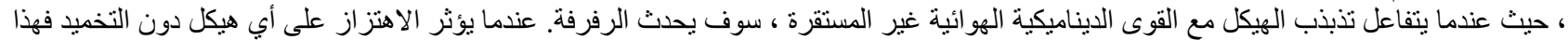

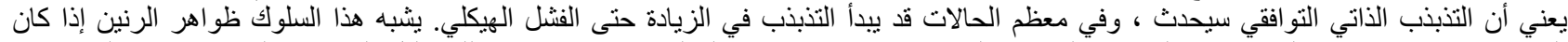

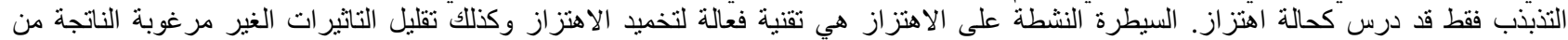

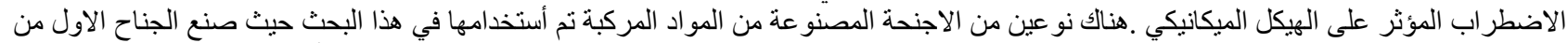

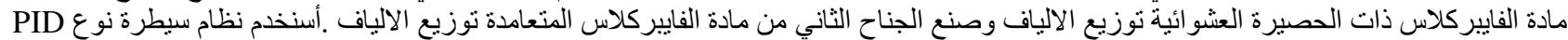

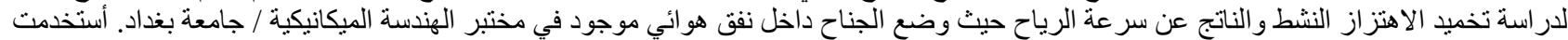

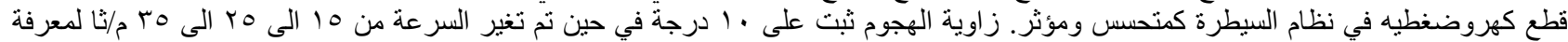

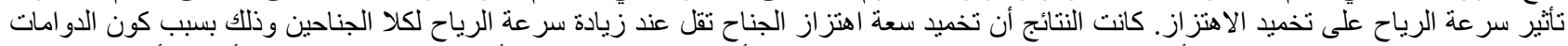

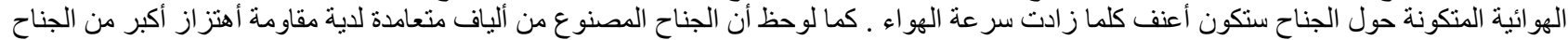

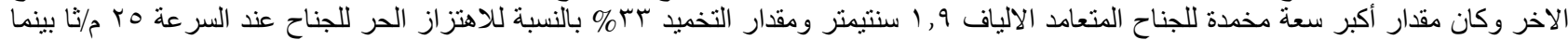

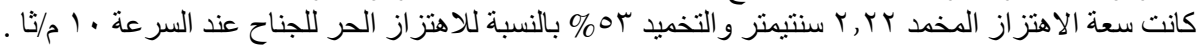

